\title{
O ZNACZENIU DYSTRYBUCJI AKTANTÓW W TŁUMACZENIU BILINGWALNYM NA PRZYKŁADZIE JĘZYKÓW NIEMIECKIEGO POLSKIEGO
}

\begin{abstract}
Zarys treści: Celem artykułu jest wykazanie ważności dystrybucji aktantów w tłumaczeniu bilingwalnym na przykładzie języków niemieckiego i polskiego. Dlatego przeprowadzona została analiza kontrastywna pod kątem możliwości i/lub konieczności uszeregowania aktantów w poszczególnych polach zdaniowych w zależności od formy szyku (podstawowy, nienacechowany, pragmatyczny), reprezentacji morfologicznej aktantów oraz w języku niemieckim parametru określoności. Istotnym punktem artykułu jest analiza kompensacji systemowej kategorii określoności w języku polskim oraz możliwości wykorzystania tej kompensacji w procesie tłumaczenia.
\end{abstract}

Słowa kluczowe: tłumaczenie, tłumaczenie bilingwalne, dystrybucja aktantów

$\mathrm{N}$ iniejszy artykuł stawia sobie za cel prezentację mechanizmów determinujących linearyzację aktantów (wg gramatyki tradycyjnej są to podmiot $\mathrm{i}$ dopełnienia) i zbadanie wpływu tych mechanizmów na proces tłumaczenia bilingwalnego na przykładzie języków wymienionych w tytule. Przedmiotem artykułu jest wyodrębnienie nie tyle podobieństw, co różnic oraz wskazanie źródeł potencjalnych błędów i nieścisłości lub nieadekwatności w przekładzie bilingwalnym odnośnie do szyku aktantów.

Wspomniane właściwości systemowe zostaną przeanalizowane w odniesieniu do szyku aktantów, który wg konwencji prezentowanej w niniejszym artykule może występować w następujących postaciach, jako: 
1. szyk podstawowy - konstytuujący się bezpośrednio w oparciu na walencji czasownika głównego/pełnego ${ }^{1}$ i dotyczący podstawowego uszeregowania wyłącznie aktantów reprezentowanych przez rzeczowniki $\mathrm{z}$ rodzajnikiem określonym;

2. szyk nienacechowany pragmatycznie (neutralny) - wynikający pośrednio $\mathrm{z}$ walencji czasownika głównego/pełnego oraz zasady bliskości składniowej (por. Helbig, Buscha 2001: 477 n.; Hoberg 1981: 63; Jung 1988: 137); ponieważ szyk nienacechowany nie odznacza się żadną restrykcyjnością co do statusu walencyjnego, reprezentacji morfologicznej oraz określoności, może więc zawierać elementy zaopatrzone zarówno parametrem określoności, jak i nieokreśloności, i zawierać nie tylko elementy reprezentowane przez rzeczowniki, lecz także przez zaimki;

3. szyk nacechowany pragmatycznie, określany też szykiem pragmatycznym - zawsze wynikający z kontekstu językowego i/lub sytuacyjnego; dla prezentacji mechanizmów, leżących u jego podstaw, uwzględniony zostanie podział zdania wg struktury komunikacyjnej na obszar tematyczny i rematyczny.

Powyższe rozgraniczenie między trzema formami szyku ma na celu ułatwienie procesu translacji, odnoszącego się do linearnego uporządkowania elementów pozycyjnych.

Linearna procedura porządkowa dotyczy uszeregowania poszczególnych elementów zdania głównie w odniesieniu do:

1. ich przyporządkowania do pól zdaniowych,

2. ich linearyzacji w poszczególnych polach zdaniowych.

Ad 1

Pola zadaniowe wyznaczane są przez orzeczenie, tzn. wyłącznie odmienną część lub jego odmienną część wraz z częścią nieodmienną (część odmienna i część nieodmienna tworzą kompleks orzeczeniowy).

Pozycja zarówno odmiennej, jak i nieodmiennej części orzeczenia, o ile ta ostatnia występuje, jest w języku niemieckim ściśle restrykcyjna.

\footnotetext{
${ }^{1} \mathrm{Nt}$. wpływu walencji czasownika pełnego/głównego na szyk wyrazów w zdaniu, zasady bliskości składniowej oraz rozgraniczenia szyku ,podstawowego” od „nienacechowanego" por. J. Barański, Zur Differenzierung zwischen 'Grundfolge' und 'unmarkierter Abfolge' im Deutschen und im Polnischen. Versuch einer typologisch-kontrastiver Analyse, [w:] Phänomene im syntaktisch-semantischen Grenzbereich, red. L. Cirko, M. Grimmberg, Wrocław, 25 stron manuskryptu (w druku). O teorii walencji bez szczegółowej analizy wpływu walencji na szyk por. U. Engel 1996, 2004; J. Erben 1972; G. Helbig, M. D. Stepanova 1978; G. Helbig, W. Schenkel 1991.
} 
Odmienna część orzeczenia może zajmować drugie miejsce w zdaniu (Zweitstellung), ostatnią pozycję w zdaniu podrzędnie złożonym $\mathrm{z}$ elementem wprowadzającym $^{2}$ (Letztstellung) lub pierwsze miejsce w zdaniu (Erststellung) (por. Helbig, Buscha 2001: 473 n.)

Nieodmienna część orzeczenia - bezokolicznik, imiesłów II, przedrostek rozdzielnie złożony, negacja zdaniowa, „nomeny złożeniowe”3 - może zajmować ostatnie miejsce w zdaniu, a gdy zdanie podrzędne rozpoczyna się od „subjunktora” (Subjunktor ${ }^{4}$ ), nieodmienna część orzeczenia może zajmować przedostatnie miejsce $\mathrm{w}$ takim zdaniu, tuż przed odmienną częścią orzeczenia ${ }^{5}$ (por. Helbig, Buscha 2001: 474 n.).

W zależności od pozycji, które zajmują elementy orzeczenia w zdaniu niemieckim, wyodrębniają się trzy pola zdaniowe: Mittelfeld, Vorfeld, Nachfeld (por. Engel 1996: 303, Duden 1998: 819), konstytuowane przez klamrę zdaniową (składającą się z części lewej = linker Klammerteil [1K] oraz z części prawej = rechter Klammerteil $[\mathrm{rK}])$, którą stanowi np. kompleks orzeczeniowy (reiner Rahmen $^{6}=$,klamra czysta”) lub spójnik zdania podrzędnie złożonego (=Subjunktor) i element werbalny (gemischter Rahmen ${ }^{7}=$ „klamra mieszana”). Pod pojęciem „klamra zdaniowa” U. Engel rozumie konstrukcję, która leży u podstaw wszystkich zjawisk dotyczących szyku wyrazów, dzieląc zdanie niemieckie na trzy ,pola”: Vorfeld, Mittelfeld, Nachfeld ${ }^{8}$.

(1)

Der Vater hat seiner Tochter einen modernen Wagen geschenkt zu ihrem 18. Geburtstag.

${ }^{2} \mathrm{Z}$ wyjątkiem bezokolicznika zastępczego (=Ersatzinfinitiv), przed którym odmienna część orzeczenia występuje bezpośrednio (por. G. Helbig, J. Buscha 2001: 98).

${ }^{3} \mathrm{~W}$ literaturze przedmiotu występują konkurencyjne określenia tej kategorii gramatycznej, np.: Funktionsnomina (= ,nomeny funkcyjne”), nominale Bestandteile (= „nominalne części składowe"). Sformułowanie zawarte w cudzysłowie jest autorskim tłumaczeniem terminu, który stosuje U. Engel (= Gefügenomina, por. np. 1996: 325 lub 407-409). Termin występujący w publikacjach U. Engela wydaje się w najbardziej adekwatny sposób określać funkcję tej kategorii.

${ }^{4}$ Więcej na temat tej kategorii gramatycznej por. U. Engel 1996: 708, 737.

5 Z wyjątkiem konstrukcji Ersatzinfinitiv (por. G. Helbig, J. Buscha 2001: 98) - wówczas odmienna część orzeczenia występuje bezpośrednio przed kompleksem orzeczeniowym.

${ }^{6}$ Por. Hoberg 1981: 31

${ }^{7}$ Por. Ibidem.

${ }^{8}$ Unter dem Begriff Satzklammer versteht U. Engel eine Konstruktion, die ,allen Folgeerscheinungen im Satz zugrunde gelegt wird. Diese Klammer, aus verbalen Bestandteilen, im Nebensatz zusätzlich aus dem Subjunktor [...] gebildet, teilt den deutschen Satz in drei Felder: Vorfeld, Mittelfeld, Nachfeld. (U. Engel 1996: 303). 
Vorfeld IK Mittelfeld r r $\quad$ Nachfeld

Według DPG (1999: 521) język polski charakteryzuje się podziałem struktury zdania na „pole lewe” (= linkes Feld) i ,pole prawe” (= rechtes Feld), które są odgraniczane przez orzeczenie lub kompleks orzeczeniowy.

Co się tyczy pozycji orzeczenia w języku polskim, to mogłoby się wydawać, że jest ona zdeterminowana $\mathrm{w}$ mniejszym stopniu niż $\mathrm{w}$ języku niemieckim, tzn. odznacza się mniejszą restrykcyjnością. W trakcie thumaczenia na język polski tłumacz może być skonfrontowany z dylematem, w którym miejscu struktury zdania umieścić orzeczenie. Dlatego też wydaje się słuszne pytanie o restrykcyjność pozycyjności orzeczenia w polszczyźnie. Czy orzeczenie jest ruchome, czy też odwrotnie: orzeczenie jest stabilne i tworzy centrum zdania? O centralnej pozycji orzeczenia niech świadczy niniejszy cytat:

den beiden Klammerteilen des Deutschen entspricht [...] im Polnischen [...] die verbale Mitte. Den drei Feldern des Deutschen entsprechen dann im Polnischen zwei Felder - ein linkes und ein rechtes ${ }^{9}$ (U. Engel 2001: 88).

Pozycja orzeczenia w języku polskim jest więc także ściśle określona, tworząc centrum werbalne. Permutacjom wokół orzeczenia podlegają zatem nominalne elementy pozycyjne, których restrykcyjność w języku polskim, ze względu na bardziej rozbudowany system fleksyjny, jest niższa niż restrykcyjność permutacji nominalnych elementów pozycyjnych języka niemieckiego. Polszczyzna dopuszcza większą liczbę permutacji, co nie znaczy jednak, że uporządkowanie nominalnych elementów pozycyjnych języka polskiego jest dowolne i że nie jest zdeterminowane przez żadne reguły składniowe.

Ad 2

Aby uwydatnić relewancję uszeregowania linearnego nominalnych elementów pozycyjnych zdania w procesie tłumaczenia i wykazać wpływ tegoż uszeregowania na adekwatność przekładu, należy za punkt wyjścia przyjąć szyk podstawowy, leżący u podstaw innych form szyku (tzn. szyku nienacechowanego i/lub szyku pragmatycznego), które są jego pochodnymi.

Szyk podstawowy, rozumiany w niniejszym artykule jako podstawowe uszeregowanie reprezentowanych przez rzeczowniki aktantów (podmiotu i dopełnień), przedstawia się następująco: w języku niemieckim podmiot występuje w obszarze określanym jako Vorfeld, a okoliczniki uszeregowane są w Mittelfeld w następującym porządku: dopełnienie w celowniku - dopełnienie $\mathrm{w}$ bierniku - dopełnienie $\mathrm{z}$ przyimkiem/dopełnienie $\mathrm{w}$ dopełniaczu ${ }^{10}$.

9 „Obu częściom klamry zdaniowej w niemczyźnie odpowiada [...] w języku polskim [...] centrum werbalne (czasownikowe). Trzem polom w niemczyźnie odpowiadają zatem w polszczyźnie dwa pola - lewe i prawe" [J.B.].

${ }^{10}$ Ukośnik sygnalizuje, że w stronie czynnej dopełnienia te nie występują równocześnie. 
Szyk podstawowy języka polskiego odznacza się pierwszą pozycją podmiotu w „polu lewym”, gdzie podmiot występuje samodzielnie. Istnieje możliwość okurencji podmiotu z innymi elementami w ,polu lewym”, lecz wówczas nie mamy już do czynienia z szykiem podstawowym, lecz z szykiem nienacechowanym (neutralnym) lub nacechowanym (pragmatycznym). Podstawowym polem zdaniowym dla dopełnien jest ,pole prawe”, gdzie podstawowy porządek dopełnień przedstawia się następująco: dopełnienie w celowniku - dopełnienie w bierniku - dopełnienie w narzędniku - dopełnienie z przyimkiem - dopełnienie w dopełniaczu.

Szyk podstawowy, poniekąd wyidealizowany, gdyż wyizolowany z kontekstu i abstrahujący od aktantów reprezentowanych przez zaimki oraz od okoliczników, charakteryzuje się ponadto reprezentacją aktantów wyłącznie poprzez rzeczowniki z parametrem określoności, (restrykcja określoności dotyczy języka niemieckiego, gdyż polszczyzna nie wyróżnia gramatycznej kategorii określoności, związanej $\mathrm{z}$ obligatoryjnym występowaniem jej eksponentów morfologicznych w postaci rodzajników: określonego, nieokreślonego, zerowego - „keine isomorphe Entsprechung im Polnischen”11, DPG 1999: 802 n.). Przykładowe zdania w szyku podstawowym mogą być przedstawione następująco:

(2a)

Der Nachbar

\begin{tabular}{lcc} 
hat dem Kollegen & das Auto geliehen. \\
$\begin{array}{l}\text { Podmiot } \\
\text { Vorfeld }\end{array}$ & dop. w celowniku & dop. w bierniku \\
& \multicolumn{2}{c}{ Mittelfeld }
\end{tabular}

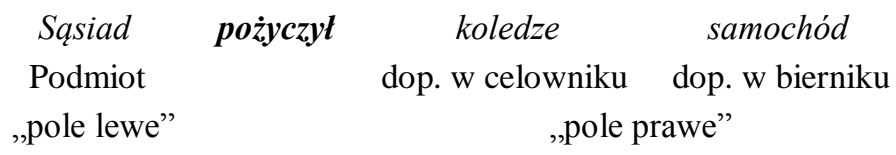

Przy założeniu, że znane są zasady konstytuujące szyk podstawowy, tłumaczenie zdań występujących $\mathrm{w}$ tym właśnie szyku nie powinno przysporzyć większych problemów. Ponieważ jednak szyk ten jest wyidealizowany i wyizolowany z kontekstu, nie odznacza się on tak wysokim stopniem frekwencyjności jak szyk neutralny oraz szyk nacechowany pragmatycznie, dlatego dalsza część artykułu zostanie poświęcona analizie przekładalności przykładowych zdań występujących w formach szyku o wyższej frekwencyjności.

Szyk neutralny w przeciwieństwie do podstawowego dopuszcza pronominalizację nieakcentowanych aktantów. Między językiem niemieckim a językiem polskim istnieją jednak rozbieżności w linearyzacji nieakcentowanych zaimków. O ile w niemczyźnie nieakcentowany zaimek w funkcji podmiotu może

11 „Brak izomorficznego odpowiednika w polszczyźnie” [J.B.]. 
występować w Vorfeld, o tyle jego polski odpowiednik nie zajmuje pierwszej pozycji w zdaniu o szyku nienacechowanym (por. Gaca 2001: 93 n.):

(3)

Er hat dem Kollegen das Auto geliehen.

Pożyczył koledze samochód.

Uwzględnienie zaimka w funkcji podmiotu możliwe jest natomiast w szyku nacechowanym pragmatycznie (w szyku pragmatycznym):

(4a)

On pożyczył koledze samochód.

Powyższe zdanie jest zatem ekwiwalentem niemieckiego zdania $\mathrm{z}$ akcentowanym zaimkiem, a więc zdania również w szyku pragmatycznym.

(4b)

Er hat dem Kollegen das Auto geliehen.

Pronominalizacja dopełnień nieakcentowanych również skutkuje zmianą szyku podstawowego na neutralny. W języku niemieckim powoduje ona następujące, oczywiste uszeregowanie zaimków nieakcentowanych: zaimek w bierniku przed zaimkiem w celowniku.

(5a)

Der Nachbar hat es ihm geliehen.

Zamiana rzeczowników na zaimki nieakcentowane w zdaniu polskim wydaje się wzmacniać restrykcyjność szyku, gdzie dopełnienie w celowniku występuje przed dopełnieniem w bierniku:

(5b)

Sąsiad pożyczył mu go. vs. *Sąsiad pożyczył go mu.

W języku polskim istnieje natomiast możliwość umieszczenia obu zaimków w „polu lewym”, między podmiotem a odmienną częścią orzeczenia:

(6)

Sąsiad mu go pożyczył, gdy wyjeżdżał do Niemiec.

Der Nachbar hat es ihm geliehen, als er nach Deutschland abfuhr.

Gdy orzeczenie w języku polskim zajmuje ostatnie miejsce w zdaniu, wówczas jest akcentowane:

(7)

Sąsiad mu go pożyczyl (a nie sprezentował).

Dla osiągnięcia podobnego efektu w języku niemieckim istnieją następujące możliwości uszeregowania elementów w procesie translacji. Usytuowanie imiesłowu II w Vorfeld, co automatycznie powoduje skierowanie nań akcentu:

(7a)

Geliehen hat es ihm der Nachbar (und nicht geschenkt).

lub pozostawienie go $\mathrm{W}$ pozycji elementu zamykającego klamrę zdaniową. Wówczas możliwe jest jego zaakcentowanie wyłącznie w języku mówionym. 
W języku pisanym można jedynie mówić o zaakcentowaniu kontrastywnym (czyli poprzez kontrast).

(7b)

Der Nachbar hat es ihm geliehen, und nicht geschenkt.

Co się tyczy umieszczenia zaimka w funkcji biernika przed zaimkiem w funkcji celownika w języku polskim, to jest ono możliwe jedynie pod warunkiem zaakcentowania celownika:

(8)

Sąsiad pożyczył go jemu.

Akcentowanie zaimka w rodzaju męskim i nijakim jest jednak uwarunkowane morfologicznie i wymaga użycia jego pełnej formy. Nieakcentowany zaimek nie może również występować na pierwszym miejscu w zdaniu. Aby móc być umieszczonym w tym właśnie miejscu, musi być akcentowany oraz zaopatrzony odpowiednią (tj. pełną) formą morfologiczną (por. Gaca 2001: 112).

(9)

Jemu sąsiad pożyczył samochód. vs. *Mu sąsiad pożyczył samochód.

Również w niemieckim Vorfeld mogą występować wyłącznie akcentowane zaimki jako dopełnienia w celowniku i bierniku (por. Engel 2004: 170). W przeciwieństwie do polszczyzny, zaakcentowanie zaimka w języku niemieckim nie jest uwarunkowane morfologicznie, gdyż w niemczyźnie nie rozróżnia się krótkich i pełnych form zaimków, dlatego jednoznaczne zaakcentowanie możliwe jest jedynie $w$ języku mówionym poprzez odpowiednią intonację. Nie oznacza to jednak, iż w niemczyźnie pisanej umieszczenie zaimka w Vorfeld jest błędem, lecz świadczy o tym, że zaimek ten jest akcentowany (por. Engel 2004: 170) i thumacząc na język polski należy zastosować formę pełną z fakultatywnym „wskaźnikiem (parametrem) emfazy” to (= Emphasenindikator to, por. Gaca 2001: 110). Poniższe zdania są ekwiwalentne:

(10)

Ihm hat der Nachbar das Auto geliehen, (und nicht ihr.)

(To) Jemu sąsiad pożyczył samochód, (a nie jej.)

Adekwatność powyższego tłumaczenia nie dotyczy wyłącznie zastosowania i pozycyjności zaimków, lecz także odpowiada usytuowaniu rzeczowników jako aktantów wg podziału struktury komunikacyjnej zdania na obszar tematyczny (temat) i obszar rematyczny (remat).

Temat, najogólniej rzecz ujmując, dotyczy informacji znanych lub bliżej określonych, remat - nieznanych lub bliżej nieokreślonych. Zasadniczo informacje znane występują przed nieznanymi (stąd kolejność temat/remat), co potwierdza następujący cytat: 
„In der Regel steht dann das Thema links, das Rhema rechts; Abweichungen von dieser linearen Ordnung sind möglich, sie werden vor allem durch spezifische Gewichtung [...] bewirkt"12 (U. Engel 2001: 72)

Kolejność ta (temat/remat) występuje automatycznie w szyku podstawowym, którą U. Engel (2004: 173) określają jako automatische Gewichtung (= „automatyczny układ ważności komunikacyjnej poszczególnych elementów" - J. B.). Nie jest ona jednak obligatoryjna i dopuszczalne jest jej przestawienie na remat/temat.

Podział na obszar tematyczny i obszar rematyczny jest w obu językach rozbieżny. Według DPG (1999: 521) obszar tematyczny w języku niemieckim przypada na Vorfeld i na lewą część Mittelfeld, lecz lewa część Mittelfeld może pokrywać się z obszarem neutralnym. Obszar rematyczny obejmuje prawą część Mittelfeld oraz Nachfeld. W języku polskim obszar tematyczny to „pole lewe”, a rematyczny to „pole prawe”, jednak zarówno prawa część „pola lewego”, jak i lewa część „pola prawego” mogą pokrywać się z obszarem neutralnym. Podział ten można przedstawić następująco:

(11)

$$
\begin{aligned}
& \text { obszar } \\
& \text { neutralny }
\end{aligned}
$$

Ihm hat der Nachbar das Auto geliehen. (und nicht ihr)

Obszar tematyczny obszar rematyczny

Obszar neutralny

Jemu sąsiad pożyczył samochód.

Obszar tematyczny obszar rematyczny

Podział na obszar tematyczny i rematyczny motywuje także uszeregowanie elementów z parametrem określoności przed elementami z parametrem nieokreśloności w szyku nienacechowanym (neutralnym), gdzie np. dopełnienie w celowniku, reprezentowane przez rzeczownik z parametrem nieokreśloności, zajmuje pozycję neutralną za dopełnieniem w bierniku zaopatrzonym parametrem określoności:

Der Nachbar hat das Auto einem Kollegen geliehen.

12 ,Z reguły temat występuje po lewej stronie, remat po prawej; odstępstwa od tego linearnego porządku są możliwe, gdy umotywowane zostaną poprzez szczególne zaakcentowanie znaczenia określonego/nych elementu/ów." [J.B.]

[Zaakcentowanie znaczenia pewnych elementów może być rozumiane jako specyficzny układ ważności komunikacyjnej poszczególnych elementów pozycyjnych - J.B.] 
Ponieważ w przeciwieństwie do języka niemieckiego fraza nominalna języka polskiego nie rozróżnia kategorii gramatycznej określoności, która byłaby związana z obligatoryjnym występowaniem jej morfologicznych eksponentów w formie rodzajników (określonego, nieokreślonego i zerowego), pełniących funkcje parametrów określoności (por. przyp. 11), pojawia się istotne z linwistycznego punktu widzenia pytanie o możliwości kompensacji systemowej tej kategorii gramatycznej (por. Sadziński 1995/1996: 70-123; DPG 1999: 803 n.), a z przekładoznawczego punktu widzenia pytanie o wykorzystanie tychże możliwości kompensacji systemowej w procesie translacji.

Polszczyzna dysponuje leksematycznymi odpowiednikami rodzajników, którymi dla rodzajnika określonego (por. Sadziński 1995/1996: 70-87) są zaimki wskazujące w liczbie pojedynczej ten, $t a, t o$, w liczbie mnogiej $c i$ (rodzaj męskoosobowy), te (rodzaj niemęskoosobowy) lub o nieco archaicznym brzmieniu (1.p.) ów, owa, owo, (1.m.) owi, owe. Ponieważ są to zaimki wskazujące, występują, rzecz jasna, w zastosowaniu wskazującym i odpowiadają przede wszystkim zaimkom wskazującym języka niemieckiego (dieser Nachbar ten sąsiad) lub akcentowanym rodzajnikom określonym w funkcji wskazującej (der Nachbar - ten sąsiad) (por. DPG 1999: 802). Dlatego rodzajniki nieakcentowane nie są thumaczone na język polski, co ilustruje poniższy negatywny przykład:

Der Nachbar hat dem Kollegen das Auto geliehen.

*Ten sąsiad pożyczył temu koledze ten samochód.

Możliwe jest jednak tłumaczenie akcentowanych rodzajników w funkcji wskazującej.

(13a)

Der Nachbar hat dem Kollegen das Auto geliehen.

Ten sąsiad pożyczył temu koledze samochód.

Morfologicznymi odpowiednikami rodzajników nieokreślonego i zerowego są w polszczyźnie (por. Sadziński 1995/1996: 87-123) przymiotniki nieokreślone (1.p.) jakiś, jaka, jakieś (l.m.) jacyś, jakieś lub (1.p.) pewien, pewna, pewne, (l.m.) pewni, pewne.

Zdaniu (12) może więc odpowiadać tłumaczenie w następującej formie:

Sąsiad pożyczył samochód jakiemuś koledze.

$\mathrm{W}$ obu językach dopełnienia $\mathrm{w}$ celowniku $\mathrm{z}$ parametrem nieokreśloności występują za biernikiem z parametrem określoności. Ponieważ morfologiczny eksponent nieokreśloności jest w języku polskim (podobnie jak parametr określoności) fakultatywny, gdyż nie pełni funkcji rodzajnika, wydaje się możliwa 
kompensacja poprzez pozycyjność, która opiera się właśnie na podziale zdania na temat i remat. Element nieokreślony nie musi więc być zaopatrzony morfologicznym eksponentem kompensującym rodzajnik nieokreślony, gdyż jego nieokreśloność może zostać wyrażona poprzez postpozycję względem elementu określonego:

$$
\begin{array}{ccc}
\text { Sąsiad } \quad \text { pożyczył } & \text { samochód } & \text { temat } \\
& & \begin{array}{c}
\text { koledze. } \\
\text { (=elemat }
\end{array} \\
& & \text { (=element nieokreślony })
\end{array}
$$

Przestawienie kolejności elementów z parametrami określoności ( $\mathrm{z}$ temat/remat na remat/temat) powoduje zmianę na szyk nacechowany pragmatycznie, gdyż usytuowanie w języku niemieckim elementu określonego za elementem nieokreślonym powoduje zaakcentowanie elementu określonego. Oddając tę samą treść w języku polskim należy obligatoryjnie zaakcentować element nacechowany, co w języku pisanym jest możliwe poprzez wyróżnienia graficzne (lecz nie w każdym rodzaju tekstu), a w języku mówionym poprzez intonację:

Der Nachbar hat einem Kollegen das Auto geliehen.

Sąsiad pożyczył jakiemuś koledze samochód.

Wyrażenie nieokreśloności może odbyć się więc $\mathrm{w}$ drodze kompensacji poprzez pozycyjność (w ww. przypadku poprzez postpozycję), polegającą na permutacji elementu $z$ jego podstawowego obszaru okurencyjnego $w$ inne miejsce w strukturze zdania, np. tak, aby zmienił obszar z tematycznego na rematyczny, lub poprzez intonację. Ta prawidłowość może dotyczyć także podmiotu, gdy nie występuje on w swej pozycji podstawowej. Dla określoności podmiotu w niemczyźnie nie ma wprawdzie znaczenia, czy występuje w swoim obszarze podstawowym, czy nie, gdyż jego określoność każdorazowo jest realizowana poprzez rodzajnik. Podmiot w zdaniu polskim, gdy występuje w ,polu lewym”, lecz nie na pierwszym miejscu, również można deszyfrować jako nieokreślony:

Aber da riß ein Diener die Tür auf, ... (s. 104)

Ale w tejże chwili shuzacy otworzył drzwi, ... (s. 123)

Element nieokreślony, w poniższych przykładach także podmiot, nie tylko nie pojawia się $\mathrm{w}$ swym polu podstawowym, lecz może zostać usytuowany $\mathrm{w}$ „obcym polu” zdaniowym, w obszarze rematycznym, np. w prawej części Mittelfeld (zdanie niemieckie) lub w ,polu prawym” (zdanie polskie).

(17)

..., daß der Einheit seines Leibes nicht eine Seeleneinheit innewohnt, ... (s. 70)

..., że w jedności jego ciała nie mieszka jedność jego duszy, ... (s. 81) 
W stosunku do kompensacji poprzez pozycyjność istnieją jednak restrykcje, wynikające z okurencji innych elementów, w tym zdań pobocznych. Niech dla zilustrowania owej zależności posłuży przykład (18) z podmiotem i dopełnieniem w bierniku, gdzie biernik określany jest przez przydawkę w dopełniaczu. Permutacja podmiotu z parametrem nieokreśloności za biernik, wskutek czego przydawka określająca biernik i będąca elementem odniesienia dla zaimka względnego (der $=k t o ́ r y)$ występuje w jego topologicznej odległości, może spowodować zmianę znaczenia, gdy nie istnieją inne cechy dystynktywne wskazujące na związek składniowy między nimi, jak rodzaj gramatyczny czy jednoznacznie eksponowany przypadek gramatyczny. Wówczas element określający (tu zaimek względny) odnosi się do elementu występującego w jego bezpośredniej bliskości topologicznej, który poprzez tę pozycję staje się elementem określanym. Ową zależność unaoczniają następujące przykłady:

Zwei Tage später brachte ein Fuhrmann die Sachen des Fremden, der Harry Haller hieß. (s. 12)

Zwei Tage später brachte die Sachen des Fremden ein Fuhrmann, der Harry Haller hieß.

(18a)

W dwa dni później woźnica przyniósł rzeczy obcego, który nazywał się Harry Haller.

(s. 11)

W dwa dni później rzeczy obcego przyniósł woźnica, który nazywał się Harry Haller.

Zmiana pozycji elementu odniesienia względem elementu określającego spowodowała zmianę znaczenia. Pojawienie się, w wyniku powyższej permutacji, podmiotu w bezpośredniej bliskości topologicznej zaimka względnego spowodowało, że zaimek względny stał się elementem określającym podmiot, a podmiot elementem przezeń określanym. Harry Haller ,przestał być” owym obcym (= der Fremde), lecz „stał się nowym człowiekiem” - (jakimś) woźnica (= ein Fuhrman).

Kompensacja poprzez pozycyjność w języku polskim zawodzi jednak również wtedy, gdy dany element, np. podmiot, miałby występować w swoim podstawowym obszarze, $\mathrm{tj}$. w przypadku podmiotu na pierwszym miejscu w ,polu lewym". Wówczas konieczna jest kompensacja morfologiczna:

Eine spanische Tänzerin flog mir in die Arme: ... (s. 180)

Jakaś Hiszpanka sfrunęła mi w ramiona: ... (s. 213)

(20)

Da hatte ein berühmter Geschichtsphilosoph ... einen Vortrag in der Aula angekündigt.

(s. 13)

Otóż pewien sławny filozof ... zapowiedział swój wykład w auli. (s. 12) 
Reasumując, należy stwierdzić, iż podział zdania na pola zdaniowe ma znaczenie pierwszorzędne i leży u podstaw odpowiedniego uszeregowania elementów pozycyjnych. Warunkiem wyboru odpowiedniego pola dla poszczególnych elementów oraz ich odpowiedniego uporządkowania jest uwzględnienie formy szyku (podstawowego, nienacechowanego, pragmatycznego), w której dane elementy występują w zdaniu wyjściowym, a w wyniku translacji mają wystąpić w zdaniu docelowym. Następnie należy uwzględnić okurencję pozostałych elementów, reprezentację morfologiczną oraz określoność danego elementu pod kątem możliwości umieszczenia go we właściwym miejscu struktury zdania. Kolejnym warunkiem poprawności przekładu w odniesieniu do szyku jest uwzględnienie relacji składniowych, w jakich w stosunku do siebie występują elementy pozycyjne, aby nie naruszyć możliwości kombinacji ich pozycyjności.

\section{Literatura}

DPG 1999, (Deutsch-polnische kontrastive Grammatik, t. I, t. II), red. U. Engel $\mathrm{i}$ in.

Duden [G. Drosdowski (red.) i in.] 1998, 1959, Grammatik der deutschen Gegenwartssprache, Mannheim.

Engel, U. 2001, Zur Beschreibung der Wortstellung auf Grund der Dependenzstruktur. Ein Vorschlag für sprachvergleichende Untersuchungen, [w:] Wortstellung im Kontrast (deutsch-niederländisch-polnisch-ungarisch) red. U. Engel, K. Vorderwülbecke (= Deutsch im Kontrast, t. 20), Tübingen, s. $63-89$.

Engel, U. 2004, Deutsche Grammatik - Neubearbeitung, München.

Engel, U. 1996, 1988, Deutsche Grammatik, Heidelberg.

Engel, U. i in. 1999, Deutsch-polnische kontrastive Grammatik, t. I, t. II, Heidelberg.

Erben, J. 1972, 1958, Deutsche Grammatik. Ein Abriß, München.

Gaca, A. 2001, Thema und Satzanfang. Die pronominalen Kasusergänzungen im Deutschen und im Polnischen, [w:] Wortstellung im Kontrast (deutsch-niederländisch-polnisch-ungarisch), red. U. Engel, Ulrich, K. Vorderwülbecke (= Deutsch im Kontrast, t. 20), Tübingen, s. 63-89.

Helbig, G., Buscha, J. 2001, 1972, Deutsche Grammatik. Ein Handbuch für den Ausländerunterricht, Berlin.

Helbig, G., Schenkel, W. 1991, 1969, Wörterbuch zur Valenz und Distribution deutscher Verben, Tübingen.

Helbig, G., Stepanova, M. D. 1978, Wortarten und das Problem der Valenz in der deutschen Gegenwartssprache, Leipzig. 
Hoberg, U. 1981, Die Wortstellung in der geschriebenen deutschen Gegenwartssprache. Untersuchungen zur Elementenfolge im einfachen Verbalsatz (= Heutiges Deutsch I, 10), München.

Jung, W. 1988, 1966, Grammatik der deutschen Gegenwartssprache, Leipzig. Mrazović, P. 1982, Die Stellung der Satzelemente im Deutschen und Serbokroatischen. Eine kontrastive Darstellung, (= Deutsch im Kontrast, t. 1), Heidelberg.

Sadziński, R. 1995/1996, Die Kategorie der Determiniertheit und Indeterminiertheit im Deutschen und im Polnischen, Częstochowa.

\section{Źródła literackie:}

Hesse, H. 1974, Der Steppenwolf, Suhrkamp Taschenbuch Verlag 175, wyd. I. Hesse, H. 1992, Wilk stepowy, Wydawnictwo Dolnośląskie, Wrocław. Tekst według wydania Wydawnictwa Poznańskiego z 1984 roku. Przekład: G. Mycielska.

\section{Actants Distribution in Bilingual Translation. A Case Study: German-Polish and Polish-German}

\section{Summary}

The paper lays emphasis on the importance of the distribution of actants in bilingual translation from German into Polish and Polish into German. A contrastive analysis can be carried out in order to show the possibility and/or necessity of ordering actants in particular sentence patterns. This ordering will be determined by a number of parameters, such as a specific word order type (e.g. basic, neutral, pragmatic), morphological representation of actants, and, in German, the definiteness parameter. In particular, the paper focuses on the system compensation of grammatical category definiteness in the Polish language and its practical applications in the process of translation.

Keywords: translation, bilingual translation, actants distribution 